\title{
European survey of fertility and pregnancy in women with Crohn's disease: a case control study by European collaborative group
}

\author{
Coordinated by J F MAYBERRY AND I T WETERMAN
}

SUMmaRY Two hundred and seventy five patients with Crohn's disease from five countries were interviewed. Each patient was matched with a control of the same age. Of the 275 women with Crohn's disease 224 had been married at some time compared with 208 controls. The mean age at marriage was 23 years. Diagnosis of Crohn's disease was made five years later and the survey was conducted on average 16 years after marriage. Cases and controls had a similar obstetric study before diagnosis. After diagnosis there was a significant reduction in the number of children born to patients $(0.4)$ compared with controls $(0.7)$. Crohn's disease did not increase the rate of miscarriage or Caesarian section but prematurity was more common in patients $(16 \%)$ than controls $(7 \%)$. The site of disease at diagnosis did not affect these findings. Medical advice against pregnancy may be partly responsible for this reduction in fertility, but patients practised contraception less than controls and a significantly greater proportion of these $(42 \%)$ failed to become pregnant compared with controls $(28 \%)$. Crohn's disease results in subfertility.

Crohn's disease commonly affects women during the reproductive years. It has been suggested that pregnancy may exacerbate the disease ${ }^{1}$ and it is possible that such reports may have led to medical advice against pregnancy in some instances. This study reports the experience of patients across Europe compared with healthy controls. It was designed to investigate fertility and the outcome of pregnancy in patient's with Crohn's disease from different countries.

\section{Method}

\section{CENTRES}

Patients and controls from the Netherlands (100 patients and 100 controls), Wales (92), Czechoslovakia (42), Switzerland (30) and Sweden (11) participated in the study.

\section{PATIENTS}

Women who were aged between 18 and 45 years at

Address for correspondence: Dr J F Mayberry, 5 St Leonards Drive. Wollaton, Nottingham NG8 2BB.

Received for publication 14 October 1985.

Co-authors: Czechoslovakia: M Borkovec, Z Maratka, Bulovka Hospital. Praha; Switzerland: R Ammann. P Buchmann, Universitätsspital, Zurich Sweden: U Monsen, G Hellers, St Eriks Sjukhus, Stockholm; Netherlands: I T Weterman. Academisch Zickenhuis. Leiden; Wales: B Myers, R Newcombe. J Rhodes. University Hospital of Wales, Cardiff; J Morris, Bridgend General Hospital, Bridgend; B Calcraft, J Mayberry. Royal Gwent Hospital. Newport. the time of diagnosis were included in the study. A total of 275 women were interviewed together with 275 age matched controls. Controls were matched with cases for the same year of age. Of the 275 patients studied, 224 had been married at some time (Table 1) and in 207 cases they were married at the time of interview. Only 208 of the controls had been married at some time and 191 of these were married at the time of interview. In 182 pairs both patient and control were married at the time of the survey.

Details of the localisation of the patient's Crohn's disease were recorded in each country. The largest group (112) of patients were classified as having ileocaecal disease. This is largely due to the 62 patients from South Wales where this terminology may be used to describe patients with terminal ileal disease, but without gross caecal disease. In all centres extensive disease ( 32 cases) refers to patients with macroscopic involvement of two or more sites; this does not include patients with disease in the ileocaecal area only. Eighty two patients had colorectal disease and forty nine patients had small bowel disease only.

CONTROLS

In each country the controls were selected randomly from a generally healthy population drawn from administrative hospital staff or orthopaedic patients 
Table 1 Marital status and country of origin of women with Crohn's disease who took part in the European fertility study

\begin{tabular}{|c|c|c|c|c|}
\hline \multirow[b]{2}{*}{ Country } & \multirow{2}{*}{$\begin{array}{l}\text { Total number } \\
\text { of cases }\end{array}$} & \multicolumn{2}{|c|}{$\begin{array}{l}\text { People who have been } \\
\text { married at some stage }\end{array}$} & \multirow{2}{*}{$\begin{array}{l}\text { No of pairs where } \\
\text { case and control were } \\
\text { married at the } \\
\text { time of the survey }\end{array}$} \\
\hline & & Cases & Controls & \\
\hline Czechoslovakia & 42 & 38 & 39 & 37 \\
\hline Netherlands & 100 & 80 & 63 & 53 \\
\hline Sweden & 11 & 9 & 8 & 7 \\
\hline Switzerland & 30 & 18 & 16 & 11 \\
\hline Wales & 92 & 79 & 82 & 74 \\
\hline Total & 275 & 224 & 208 & 182 \\
\hline
\end{tabular}

with fractures. Medical and nursing staff were specifically excluded as controls. Subsequent analysis showed that these controls were representative of their communities, especially in their marital and reproductive activities. British women born in 1945 have 2.2 children during their reproductive life ${ }^{2}$ and this is similar to the two children born to all British controls or the $2 \cdot 2$ children born to married British controls.

\section{PREGNANCIES}

Details of the number of children born before and after diagnosis were collected for each patient, together with a history of miscarriage, prematurity and mode of delivery either vaginally or by Caesarian section. Preterm was defined as delivery more than three weeks before the expected date of birth. The same information was collected from controls. In each of the 275 matched pairs particular attention was paid to the age at diagnosis in the patient and details of the obstetric history of the control before and after that critical age were carefully noted and recorded separately for comparison with the same data for the patient.

\section{CONTRACEPTION}

Both patients and controls were asked how long they had practised contraception both before and after diagnosis. No details were collected on the contraceptive method used. Subsequent analysis was restricted to those patients who had practised contraception for six months or longer at any one time. Married women without children were asked whether they wished to have any. Details of medical advice against pregnancy or medically advised terminations were requested from both patients and controls. Patients were asked whether having Crohn's disease had any influence on their wish to have children.

INFERTILITY

In this study infertility was defined as married women who failed to become pregnant despite not practising contraception for periods of greater than six months. No account was taken of their desire to become pregnant or not.

STATISTICAL ANALYSIS

Results were examined for each centre separately but significance rates were done on aggregated data from the five countries. The main analyses were of the 224 cases and 208 controls who had been married at some time. Unpaired $t$ tests were used to compare age at marriage, numbers of children, miscarriages and pregnancies between these groups. The proportions using contraception regularly and the proportions who, despite not practising contraception, did not become pregnant were compared between cases and controls by $\chi^{2}$ with continuity correction.

Additionally paired analysis was carried out on the whole sample of 275 case control pairs and on the 182 pairs who were both married at the time of the survey. Paired $t$ tests and McNemar tests were used. These analyses gave similar results to those quoted for the unpaired analyses.

Differences in reproductive variables between patients with disease at different sites were tested by one way analysis of variance or $\chi^{2}$ as appropriate.

\section{Results}

Of the 275 patients who completed the survey 51 were single but 21 of these patients were cohabiting with someone, 207 were married, 13 divorced and four widowed. Sixty seven of the controls were single (21 cohabited), 191 were married, one woman was separated, 15 were divorced and one was widowed. Two hundred and twenty four of the patients and 208 of the controls had been 'married at some stage' and were classified as 'ever married' in the analysis. Cohabiting women were included with single women in subsequent analyses.

The mean age at marriage of the 224 patients with 
Table 2 Obstetric history of cases and controls who have been married at some time

\begin{tabular}{|c|c|c|c|c|c|c|}
\hline & \multirow{2}{*}{\multicolumn{2}{|c|}{$\begin{array}{l}\text { Before diagnosis } \\
\text { Crohn's disease }\end{array}$}} & \multicolumn{4}{|c|}{ After diagnosis Crohn's disease } \\
\hline & & & \multirow[b]{2}{*}{ Cases } & \multirow[b]{2}{*}{ Controls } & \multicolumn{2}{|c|}{ Statistical analysis } \\
\hline & Cases & Controls & & & Corrected $\chi^{2}$ & Significance \\
\hline Women $(n)$ & 224 & 208 & 224 & 208 & & \\
\hline $\begin{array}{l}\text { Women who became } \\
\text { pregnant }(n)\end{array}$ & $135(60 \%)$ & $118(57 \%)$ & $63(28 \%)$ & $83(40 \%)$ & $6 \cdot 1$ & $\mathrm{p}<0.01$ \\
\hline Babies born (n) & 271 & 250 & $94(2010)$ & 141 & & \\
\hline Mean no of children $( \pm S D)$ & $1.21( \pm 1.2)$ & $1 \cdot 20( \pm 1 \cdot 3)$ & $0.42( \pm 0 \cdot 8)$ & $0.68( \pm 1 \cdot 1)$ & & $\mathrm{p}<0.004$ \\
\hline $\begin{array}{l}\text { Mean no of miscarriages } \\
( \pm S D)\end{array}$ & $0 \cdot 21( \pm 0 \cdot 6)$ & $0 \cdot 25( \pm 0 \cdot 7)$ & $0 \cdot 15( \pm 0 \cdot 5)$ & $0 \cdot 16( \pm 0 \cdot 5)$ & & ns \\
\hline $\begin{array}{l}\text { Practised contraception } \\
>6 \text { months }\end{array}$ & $38 \%$ & $39 \%$ & $45 \%$ & $50 \%$ & & ns \\
\hline Infertile* & $25 \%$ & $29 \%$ & $42 \%$ & $28 \%$ & $9 \cdot 11$ & $\mathrm{p}<0.0025$ \\
\hline
\end{tabular}

$\mathrm{SD}=$ standard deviation.

${ }^{*}$ The definition of infertility is given in the text.

There was no significant differences between patients and controls in their obstetric history before the diagnosis of Crohn's disease in the patients.

Infertility in the control population was similar both in the periods before and after diagnosis.

Crohn's disease was $23( \pm 5)$ year compared with 23 $( \pm 4)$ in the 208 controls. The patients were diagnosed 5 years later at $28( \pm 8)$ and the survey was conducted at 39 years $( \pm 10)$ compared with 40 years $( \pm 11)$ in the controls.

\section{FERTILITY}

Our results show that Crohn's disease is associated

Table 3 Obstetric history of patients and controls in the period after diagnosis of Crohn's disease. Analysis is of all cases, patients and controls who have been married at some time, and pairs where cases and controls were married at the time of interview

\begin{tabular}{|c|c|c|}
\hline & $\begin{array}{l}\text { Mean number } \\
\text { of children }\end{array}$ & $\begin{array}{l}\text { No contraception } \\
\text { and no pregnancy } \\
\text { (infertile) }\end{array}$ \\
\hline \multicolumn{3}{|l|}{ Married at some time } \\
\hline Cases $(n=224)$ & 0.4 & $42 \%$ \\
\hline Controls $(n=208)$ & 0.7 & $28 \%$ \\
\hline Significance & $p<0.004$ & $\mathrm{p}<0.0025$ \\
\hline \multicolumn{3}{|c|}{$\begin{array}{l}\text { All cases regardless of } \\
\text { marital status }\end{array}$} \\
\hline Cases $(n=275)$ & 0.4 & $44 \%$ \\
\hline Controls $(n=275)$ & 0.5 & $33 \%$ \\
\hline Significance & $\mathrm{p}<0.006$ & $\mathrm{p}<0.005$ \\
\hline \multicolumn{3}{|c|}{$\begin{array}{l}\text { Cases and controls who were } \\
\text { married at time of survey }\end{array}$} \\
\hline Cases $(n=182)$ & 0.4 & $46 \%$ \\
\hline Controls $(n=182)$ & 0.7 & $29 \%$ \\
\hline Significance & $\mathrm{p}<0.001$ & $\mathrm{p}<0.0001$ \\
\hline
\end{tabular}

Regardless of matching Crohn's disease results in a reduction in the number of children born and an increase in infertility. with a reduction in fertility. The results reported in this section refer to 224 patients and 208 controls who were married at some stage prior to the interview. Both cases and controls were married at the mean age of 23 years which was five years before diagnosis and a mean of 16 years before interview.

The obstetric history of both patients and controls before the age of diagnosis is, as one would expect, the same (Table 2). After diagnosis patients with Crohn's disease have almost half the number of children controls do and this difference is highly significant $(p<0.004)$. This is not because of an increased number of miscarriages or greater practise of contraception. Forty two per cent of married women with Crohn's disease who took no regular contraceptive precautions failed to become pregnant compared with $28 \%$ of controls and this difference is highly significant $(\mathrm{p}<0.0025$, Table 2$)$.

If attention is restricted to the 182 patients and controls who were matched both for age and marital status at the time of interview and paired analyses are done the significance of these findings is even greater (Table 3 ). If no consideration is taken of marital status and all 275 patients and controls are studied there is still a significant difference in fertility (Table 3 ).

These findings were also true in each individual country, although they did not always reach statistical significance because of small numbers.

SITE OF DISEASE AND FERTILITY

One hundred and twelve patients had ileocaecal disease, 82 colorectal, 49 small bowel and 32 
Table 4 The effect of localisation of disease on obstetric history of women with Crohn's disease before and after diagnosis $(n=224)$

\begin{tabular}{|c|c|c|c|c|}
\hline & $\begin{array}{l}\text { Mean no of } \\
\text { children }( \pm S D)\end{array}$ & $\begin{array}{l}\text { Mean no of } \\
\text { miscarriages }( \pm S D)\end{array}$ & Contraception & Infertility \\
\hline Ileocaecal & $1 \cdot 2( \pm 1 \cdot 2)$ & $0 \cdot 3( \pm 0 \cdot 7)$ & $33 \%$ & $25 \%$ \\
\hline Colorectal & $1 \cdot 2( \pm 1 \cdot 3)$ & $0.2( \pm 0 \cdot 6)$ & $48 \%$ & $26 \%$ \\
\hline Small bowel & $1 \cdot 1( \pm 1 \cdot 3)$ & $0.05( \pm 0 \cdot 2)$ & $39 \%$ & $30 \%$ \\
\hline Extensive & $1.6( \pm 1.4)$ & $0.3( \pm 0.4)$ & $36 \%$ & $18 \%$ \\
\hline \multicolumn{5}{|l|}{ After diagnosis } \\
\hline Ileocaecal & $0.5( \pm 0.8)$ & $0.2( \pm 0.6)$ & $37 \%$ & $46 \%$ \\
\hline Colorectal & $0.3( \pm 0.7)$ & $0.03( \pm 0.2)$ & $61 \%$ & $36 \%$ \\
\hline Small bowel & $0.5( \pm 0.8)$ & $0.1( \pm 0.4)$ & $48 \%$ & $37 \%$ \\
\hline Extensive & $0.3( \pm 0.7)$ & $0.1 \quad( \pm 0.5)$ & $32 \%$ & $50 \%$ \\
\hline
\end{tabular}

$\mathrm{SD}=$ standard deviation.

There were no significant differences in obstetric history prior to diagnosis. After diagnosis there were nearly significantly less miscarriages to women with colorectal disease $(F=2 \cdot 54 ; \mathrm{df}=3$ and $220 ; \mathrm{p}=0 \cdot 06)$ and they practised contraception significantly more often than other groups $\left(x_{3}^{2}=10 \cdot 57 ; p<0 \cdot 01\right)$.

extensive disease involving more than one site. Localisation of disease has no significant influence on the number of children born to women with Crohn's disease and minimal effect on the number of miscarriages and use of contraception after diagnosis (Table 4).

\section{Pregnancies}

Forty patients with Crohn's disease had been advised by a doctor to avoid pregnancy either for a limited period or completely compared with eight controls. Twenty four patients with Crohn's disease had been advised to have their pregnancy terminated compared with 15 controls and 42 of the 275 cases expressed a wish not to have children because of their disease. Despite these comments $55 \%$ of patients took no contraceptive precautions compared with only $50 \%$ of controls (Table 2) and medical advice against pregnancy does not appear to influence contraceptive practise.

During the period before diagnosis 271 babies were born to the 224 married patients with Crohn's disease compared with 250 born to the 208 married controls during the same period (mean 1.2 babies per person). In the period after diagnosis the numbers were 94 and 141 respectively $(\mathrm{t}=-2 \cdot 89$; $\mathrm{p}<0.004)$. The conception of children by controls is similar to that expected from national data. ${ }^{2}$ Before diagnosis there were a similar number of preterm deliveries ( 28 to patients and 24 to controls who had been married at some time) and deliveries by Caesarian section (two to cases and two controls). In the period after diagnosis 15 of the 94 births to patients with Crohn's disease were preterm compared with 10 of 141 born to controls (corrected $\chi^{2}=4.7 ; p<0 \cdot(03)$. During this period 12 of the deliveries in patients were by Caesarian section compared with 11 in controls; but these figures were largely influenced by two patients, one from the Netherlands who had four Caesarian sections and one from Wales who had three and if account is taken of this significance is lost (corrected $\chi^{2}=1 \cdot 5$; not significant).

Preterm births were seen in $7 \%$ of controls which is similar to that recently reported from Europe. ${ }^{3}$ The controls chosen in the study are representative of their countries of origin.

\section{Discussion}

This international study of fertility and pregnancy in Crohn's disease is the first in which patients have been compared with controls who were matched for exact age and in whom details of marital status were recorded. It is the first time details of the obstetric history before and after the diagnosis were recorded for patients and similar periods considered for the controls.

The development of Crohn's disease by women aged between 18 and 45 years results in a significant reduction in both fertility and pregnancy. This is unaffected by the site of the disease and is not because of a greater rate of miscarriage by patients when compared with controls. Medical advice against pregnancy may be a factor, although there was no increased use of contraception by patients. The effect of disease activity, the use of drugs and surgery will be the subject of a separate study.

These findings are in contrast with those reported by Khosla et $\mathrm{al}^{4}$ who reported an infertility rate of $12 \%$ in 54 patients which was similar to that seen in the general population. Crohn also reported a 
similar finding in 1956. Kreig et al reported the obstetric history of 184 women after surgical treatment for Crohn's disease during the reproductive years. Forty seven $(26 \%)$ became pregnant but only $36(20 \%)$ delivered a baby. In our study 63 of the $224(28 \%)$ women who had been married delivered a baby after the diagnosis of Crohn's disease, compared with $40 \%$ of controls.

We have been unable to confirm the findings of Fielding and Cooke ${ }^{6}$ who reported a higher infertility in large bowel disease. In our study fertility is uniformly reduced regardless of the site of macroscopic disease, and this is similar to De Dombal's report. $^{7}$

Prematurity was significantly commoner in our patients with Crohn's disease and affected $16 \%$ of births. In Crohn's report in 1956 of 80 births to patients with Crohn's disease, $5 \%$ of deliveries were premature and in Fielding and Cooke's study, $5 \%$ of births were again premature. Together with other clinical studies these reports have resulted in the general view that Crohn's disease does not significantly affect the course of pregnancy or end in premature birth. ${ }^{8}$ In our study of 275 women with Crohn's disease there was, however, a significant increase in prematurity amongst the reduced number of conceptions after diagnosis of the disease. There is no reason to suspect that Caesarian section is more common in Crohn's disease, except perhaps where the disease has involved the perineum, cervix, and or vagina.

Crohn's disease results in subfertility and in increased chance of premature delivery. These findings are independent of the site of disease.

During this study John Mayberry was the Sir Arthur Hurst Travel Fellow of the British Digestive Foundation.

\section{References}

1 Crohn BB, Yarnis H, Korelitz BI. Regional ileitis complicating pregnancy. Gastroenterology 1956; 31: 615-28.

2 Werner B. Family size and age at childbirth: trends and projections. Population Trends 1983; 33: 4-17.

3 Boldman R, Reed DM. Worldwide variations in low birth weight. In: Reed DM, Stanley FJ, eds. The epidemiology of prematurity. Baltimore-Munich: Urban and Schwarzenberg. 1977: 39-52.

4 Khosla R, Willoughby CP, Jewell DP. Crohn's disease and pregnancy. Gut 1984; 25: 52-6.

5 Kreig H, Brunner H, Daniels V. Morbus Crohn und Schwangerschaft. Langenbecks Arch Chir, 1983; 359: 219-26.

6 Fielding JF, Cooke WT. Pregnancy and Crohn's disease. Br Med J 1970; 2: 76-7.

7 De Dombal FT, Burton IL, Goligher JC. Crohn's disease and pregnancy. $B r$ Med $J$ 1972; 3: 550-3.

8 Vender RJ, Spiro HM. Inflammatory bowel disease and pregnancy. J Clin Gastroenterol 1982; 4: 231-49. 